\title{
Secondary stroke prevention: challenges and solutions
}

\author{
This article was published in the following Dove Press journal: \\ Vascular Health and Risk Management \\ 7 August 2015 \\ Number of times this article has been viewed
}

\section{Charles Esenwa \\ Jose Gutierrez}

Department of Neurology, College of Physicians and Surgeons, Columbia University Medical Center, New York, NY, USA
Correspondence: Jose Gutierrez

Department of Neurology, College of Physicians and Surgeons,

Columbia University Medical Center, $710 \mathrm{~W}$ 168th Street, 6th floor, Suite 639, New York, NY, 10032, USA

$\mathrm{Tel}+\mathrm{I} 212305$ I7I0

Fax + I 212305374 |

Email j33233@cumc.columbia.edu
Abstract: Stroke is the leading cause of disability in the USA and a major cause of mortality worldwide. One out of four strokes is recurrent. Secondary stroke prevention starts with deciphering the most likely stroke mechanism. In general, one of the main goals in stroke reduction is to control vascular risk factors such as hypertension, diabetes, dyslipidemia, and smoking cessation. Changes in lifestyle like a healthy diet and aerobic exercise are also recommended strategies. In the case of cardioembolism due to atrial fibrillation, mechanical valves, or cardiac thrombus, anticoagulation is the mainstay of therapy. The role of anticoagulation is less evident in the case of bioprosthetic valves, patent foramen ovale, and dilated cardiomyopathy with low ejection fraction. Strokes due to larger artery atherosclerosis account for approximately a third of all strokes. In the case of symptomatic extracranial carotid stenosis, surgical intervention as close as possible in time to the index event seems highly beneficial. In the case of intracranial large artery atherosclerosis, the best medical therapy consists of antiplatelets, high-dose statins, aggressive controls of vascular risk factors, and lifestyle modifications, with no role for intracranial arterial stenting or angioplasty. For patients with small artery occlusion (ie, lacunar stroke), the therapy is similar to that used in patients with intracranial large artery atherosclerosis. Despite the constant new evidence on how to best treat patients who have suffered a stroke, the risk of stroke recurrence remains unacceptably high, thus evidencing the need for novel therapies.

Keywords: stroke mechanisms, stroke risk, hypertension, diabetes, dyslipidemia

\section{Introduction}

Stroke is defined as clinical, radiological, or pathological evidence of ischemia or hemorrhage, involving a defined cerebral vascular territory. ${ }^{1}$ In the USA, there are approximately 800,000 strokes per year, approximately 600,000 of which are recurrent events. Stroke is now the fifth leading cause of death, but it remains the number one cause of disability in the USA. ${ }^{2}$ While there has been a steady decline in stroke incidence in developed countries, incidence in low-to-middle-income countries continues to increase - accounting for $85 \%$ of the worldwide stroke burden. ${ }^{3}$

Once a stroke has occurred, treatment options are limited and only available for a short time immediately after the symptom onset. As a result, stroke prevention has been considered the mainstay in stroke management for over half a century, and despite decades of research in stroke prevention, there remain basic challenges in secondary stroke prevention. ${ }^{4}$ The literature addressing secondary stroke prevention is vast and impossible to thoroughly discuss in a single paper. This review should be viewed as a summary of the more frequent stroke mechanisms and the available evidence from randomized clinical trials for the best therapies to prevent stroke recurrence. 


\section{Ischemic stroke characterization}

Knowing the stroke etiology is a critical step in the entire process because both risk-factor modification and stroke prevention begin with appropriate characterization of the stroke mechanism. ${ }^{5}$ Depending on the stroke mechanism, the risk of recurrence and suggested algorithms to prevent stroke vary. ${ }^{6}$ The most commonly used classification scheme in ischemic stroke is the Trial of Org10172 in Acute Stroke Treatment (TOAST) classification, which includes the following five subtypes: large artery atherosclerosis (LAA), cardioembolic, small vessel occlusion (SVO), stroke of undetermined cause (ie, cryptogenic stroke), and stroke of "other" cause. ${ }^{7}$ Although other classification systems have been suggested, ${ }^{8,9}$ the TOAST classification remains the most frequently used in large epidemiological studies (Table 1).

To determine stroke etiology, a thorough workup is needed to exclude potential stroke mechanisms that may need a change in treatment. In epidemiological studies, the proportion of cryptogenic strokes varies from $13 \%$ to $50 \%$

Table I Summary of studies from different ethnic and racial groups that disclosed stroke subtype rates

\begin{tabular}{|c|c|c|c|c|c|c|c|}
\hline \multirow{2}{*}{\multicolumn{2}{|c|}{$\begin{array}{l}\text { Reference(s) Country/study } \\
\text { Prospective, population-based st }\end{array}$}} & \multirow{2}{*}{$\begin{array}{l}\text { Population } \\
\text { composition } \\
\text { udies }\end{array}$} & \multirow[t]{2}{*}{ Stroke types } & \multicolumn{3}{|c|}{ Ischemic stroke subtypes (\%) } & \\
\hline & & & & & & & \\
\hline White, Boden- & USA/NOMAS & $64 \%$ Hispanic & $77 \%$ IS & & Hispanic & Black & White \\
\hline Albala et al 2005 & Follow-up & I3\% Black & $\mathrm{I} \% \mathrm{ICH}$ & $\mathrm{CE}$ & 20 & 17 & 24 \\
\hline Collaborators, & $=4$ years & $22 \%$ White & $6 \% \mathrm{SAH}$ & LAA & 15 & 17 & 9 \\
\hline \multirow[t]{3}{*}{ Sacco et al 1998} & & & & svo & 21 & 21 & 15 \\
\hline & & & & Crypto & 43 & 44 & 51 \\
\hline & & & & Other & 1 & I & 1 \\
\hline Morgenstern, & USA/BASIC & $48 \%$ White & $83 \%$ IS & & Mexican American & White & \\
\hline Smith et al 2004 & project & $53 \%$ Mexican & $\mathrm{I} 4 \% \mathrm{ICH}$ & CE & 16 & 26 & \\
\hline Uchino, Risser & Follow-up & American & $3 \% \mathrm{SAH}$ & LAA & 14 & 15 & \\
\hline \multirow[t]{3}{*}{ et al 2004} & $=3$ years & & & svo & 21 & 17 & \\
\hline & & & & Crypto & 22 & 22 & \\
\hline & & & & Other & 2 & I & \\
\hline Broderick, & USA/GCNKSS & I8.5\% Black & $84 \%$ IS & & Black & White & \\
\hline Brott et al 1998 & Follow-up & $72.5 \%$ White & $\mathrm{I0} \% \mathrm{ICH}$ & CE & 15 & 22 & \\
\hline Schneider, & $=2-4$ years & & $4 \% \mathrm{SAH}$ & LAA & 10 & 12 & \\
\hline Kissela et al & & & $2 \%$ undetermined & svo & 18 & 15 & \\
\hline \multirow[t]{2}{*}{2004} & & & & Crypto & 54 & 49 & \\
\hline & & & & Other & 3 & 2 & \\
\hline \multirow{4}{*}{$\begin{array}{l}\text { Ohira, Shahar } \\
\text { et al 2006, 20II }\end{array}$} & USA/ARIC & $25 \%$ Black & $88 \%$ IS & & Black & White & \\
\hline & Follow-up & $75 \%$ White & $\mathrm{I} 2 \% \mathrm{ICH}$ & $\mathrm{CE}$ & 18 & 19 & \\
\hline & $=13$ years & & & svo & 30 & 13 & \\
\hline & & & & Non-SVO & 52 & 68 & \\
\hline \multirow{6}{*}{$\begin{array}{l}\text { Petty, Brown } \\
\text { et al } 1999\end{array}$} & USA/Rochester & $95 \%$ White & Not available & & Whites $(95 \%$ of the sar & nple) & \\
\hline & Follow-up & & & CE & 29 & & \\
\hline & $=4$ years & & & LAA & 16 & & \\
\hline & & & & svo & 16 & & \\
\hline & & & & Crypto & 36 & & \\
\hline & & & & Other & 3 & & \\
\hline Hajat, & England/SLSS & $71 \%$ White & $80 \%$ IS & & Black & Other & White \\
\hline Heuschmann & Follow-up & $20 \%$ Black & $\mathrm{I} 4 \% \mathrm{ICH}$ & $\mathrm{CE}$ & 17 & 17 & 31 \\
\hline et al 2010 & $=7$ years & (I3\% Caribbean & $6 \% \mathrm{SAH}$ & LAA & 9 & 11 & 10 \\
\hline Hajat, Dundas & & and $7 \%$ African) & & svo & 42 & 35 & 22 \\
\hline \multirow[t]{2}{*}{ et al 200I } & & $9 \%$ Other & & Crypto & 21 & 30 & 25 \\
\hline & & & & Other & $\mathrm{II}$ & 7 & 12 \\
\hline Feigin, Carter & New Zealand/ & $66 \%$ White & $73 \%$ ischemic & & Maori/Pacific Islander & Asian/other & White \\
\hline \multirow[t]{5}{*}{ et al 2006} & ARCSS & $20 \%$ Maori/ & $\mathrm{I} 2 \% \mathrm{ICH}$ & $\mathrm{CE}$ & 36 & 18 & 29 \\
\hline & Follow-up & Pacific Islander & $6 \% \mathrm{SAH}$ & LAA & 4 & 2 & 6 \\
\hline & $=$ I year & I4\% Asian/ & $9 \%$ undetermined & svo & 10 & 15 & 11 \\
\hline & & other & & Crypto & 46 & 61 & 51 \\
\hline & & & & Other & 4 & 4 & 3 \\
\hline
\end{tabular}


Table I (Continued)

\begin{tabular}{|c|c|c|c|c|c|c|c|c|c|}
\hline \multirow{2}{*}{$\begin{array}{l}\text { Reference(s) } \\
\text { Turin, Kita }\end{array}$} & \multirow{2}{*}{$\begin{array}{l}\text { Country/study } \\
\text { Japan/TSR }\end{array}$} & \multirow{2}{*}{$\begin{array}{l}\text { Population } \\
\text { composition }\end{array}$} & \multirow{2}{*}{$\begin{array}{l}\text { Stroke types } \\
67 \% \text { IS }\end{array}$} & \multicolumn{6}{|c|}{ Ischemic stroke subtypes (\%) } \\
\hline & & & & & Japanese & & & & \\
\hline et al 2010 & Follow-up & & $22 \% \mathrm{ICH}$ & CE & 23 & & & & \\
\hline Kita, Turin & $=16$ years & & $\mathrm{I0} \% \mathrm{SAH}$ & svo & 54 & & & & \\
\hline \multirow[t]{2}{*}{ et al 2007} & & & $1 \%$ undetermined & Non-SVO & 21 & & & & \\
\hline & & & & Other & 2 & & & & \\
\hline \multicolumn{10}{|c|}{ Cross-sectional, hospital-based studies } \\
\hline Gutierrez, & USA/JMH & $53 \%$ Hispanic & $83 \%$ IS & & Hispanic & Black & Caribbea & n Black & White \\
\hline \multirow[t]{5}{*}{ Koch et al 2013} & Sample & $23 \%$ African & $\mathrm{I} \% \mathrm{ICH}$ & CE & 38 & 22 & 23 & & 44 \\
\hline & size $=473$ & American & & LAA & 22 & 23 & 31 & & 15 \\
\hline & & I3\% Black & & svo & 17 & 25 & 28 & & 19 \\
\hline & & Caribbean & & Crypto & 13 & 13 & 13 & & 12 \\
\hline & & II\% White & & Other & 5 & 16 & 5 & & 10 \\
\hline Sharma, & Singapore & 74.2\% Chinese & Not available & & Chinese & & Malay & & Indian \\
\hline Tsivgoulis & Sample & 16.6\% Malay & & $\mathrm{CE}$ & 8 & & 7 & & 4 \\
\hline \multirow[t]{6}{*}{ et al 2012} & size $=48 \mathrm{I}$ & $9.2 \%$ Indian & & LAA & 12 & & 18 & & 25 \\
\hline & & & & SVO & 52 & & 43 & & 25 \\
\hline & & & & Crypto & 26 & & 30 & & 39 \\
\hline & & & & Other & 2 & & 2 & & 7 \\
\hline & & & & & Guayaquil & Santiago & Buenos a & ires & Bogota \\
\hline & & & & & & & Whites & Natives & \\
\hline Saposnik and & South America & Mix of & $65 \%$ IS & CE & 14 & 33 & 20 & 22 & 18 \\
\hline \multirow[t]{4}{*}{ Del Brutto 2003} & $\mathrm{~N}=912$ & mestizos, & $34 \% \mathrm{ICH}$ & LAA & 7 & 33 & 11 & 13 & 19 \\
\hline & (Meta-analysis & whites and & I\% Other & SVO & 43 & 14 & 48 & 36 & 19 \\
\hline & of hospital-based & natives & & Crypto & 30 & 15 & 16 & 21 & 29 \\
\hline & samples) & & & Other & 6 & 5 & 5 & 8 & 6 \\
\hline
\end{tabular}

Notes: Stroke subtypes vary across different populations. Demographic information may be helpful in guiding workup for stroke subtypes. The different proportions of stroke subtypes in each of the reported groups underscore the burden of certain risk factors in these populations and how it may lead to targeted strategies for secondary stroke prevention from a public health perspective. With kind permission from Springer Science+Business Media: Curr Cardiovasc Risk Rep, An epidemiological perspective on race/ethnicity and stroke, 9, 20I5, 19, Sevush-Garcy J, Gutierrez J, Table I.93

Abbreviations: CE, cardioembolism; crypto, cryptogenic; ICH, intracranial hemorrhage; IS, ischemic stroke; LAA, large artery atherosclerosis; SAH, subarachnoid hemorrhage; SVO, small vessel occlusion.

according to the workup undertaken. ${ }^{10,11}$ This underscores the need to carry out an exhaustive workup of patients with strokes.

Stroke attributed to LAA is defined as infarction distal to a large vessel stenosis. Frequent sites for atherosclerotic plaques include the aortic arch and ascending aorta, the extracranial carotid artery, and the proximal arteries in the Circle of Willis (Figures 1 and 2). ${ }^{12-14}$ Ischemia most commonly results from distal embolization of thrombotic products, a so-called artery-to-artery embolism, but it can also be caused by hypoperfusion of brain tissue distal to a severely stenotic or occluded vessel or from branch occlusive disease (Figures 1-3).

To define a stroke as cardioembolic, a clear cardiac source of embolism must be established. The most common etiologies of cardioembolic stroke are atrial fibrillation, valvular heart disease, large myocardial infarction (MI), or dilated cardiomyopathy. ${ }^{15-18}$ On the other hand, strokes that have an associated proximal large vessel stenosis, or that appear most consistent with a lacunar syndrome, can also result from cardioembolism, highlighting the challenges in determining a precise stroke mechanism. ${ }^{19,20}$ Atrial fibrillation, if paroxysmal, may be elusive. Prolonged cardiac monitoring in patients with stroke deemed "cryptogenic" may reveal occult atrial fibrillation in up to a fifth of patients, compared to only $2 \%$ with 7 -day cardiac monitoring. ${ }^{21,22}$ Consequently, a true cryptogenic stroke should typically exclude the presence of occult atrial fibrillation, particularly in subjects $>60$ years and those with evidence of prior cortical infarcts. ${ }^{23}$

Stroke from SVO is typically referred to as lacunar stroke, which in modern practice is not limited to a specific size cutoff, but rather defined by anatomical location and a typical lacunar syndrome. ${ }^{19,24}$ The typical underlying arterial pathology in lacunar infarcts includes microatheroma of the penetrating arteries (most common in the largest infarcts), lypohyalinosis (more frequent in small infarcts), microembolism, or branch occlusive disease (Figure 3). 

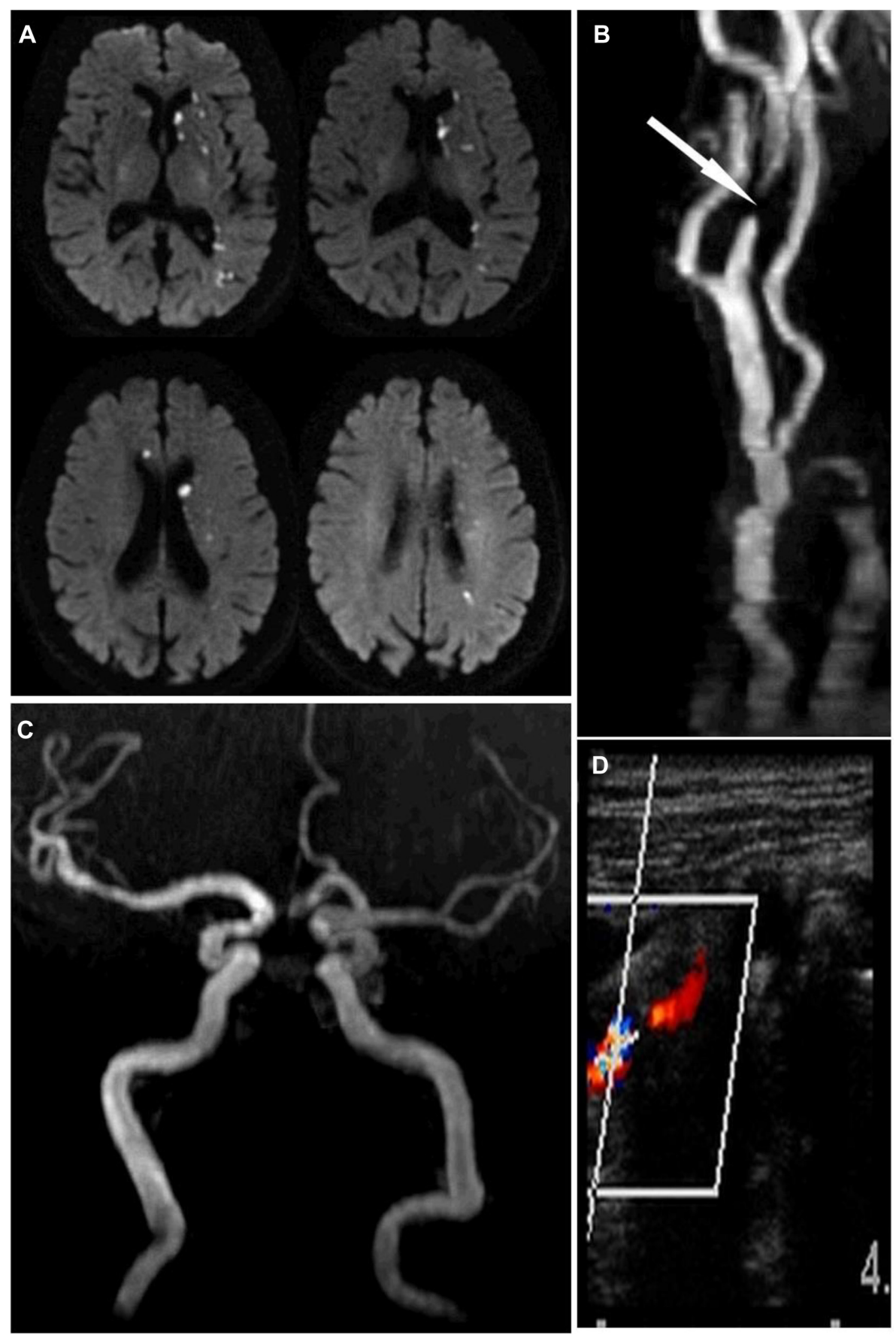

Figure I Stroke and extracranial carotid atherosclerosis.

Notes: A man in his 90 s came to the hospital with sudden onset of right-sided weakness and difficulty finding words. On exam, he was found aphasic with mild right-sided hemiparesis. (A) A brain magnetic resonance image showed evidence of scattered infarcts over the left hemisphere and a small infarct in the territory of the right anterior cerebral artery. (B) The neck magnetic resonance angiograph showed a flow gap in the left extracranial proximal internal carotid artery (arrow). (C) The brain magnetic resonance angiograph showed the lack of the right proximal segment of the anterior cerebral artery, thus explaining the presence of bi-hemispheric infarcts attributable to left extracranial carotid stenosis through embolization of the anterior communicating artery. (D) A neck artery Doppler confirmed the degree of stenosis ( $>80 \%$ ) and the patient underwent carotid endarterectomy and was discharged home after the initial neurological deficits resolved.

More recent evidence suggests, however, that SVO and LAA may be the different phenotypic expression of the same underlying intracranial arterial disease, with SVO representing perhaps an earlier form of the disease. ${ }^{25-27}$ This fact may also explain why the medical therapy for those with SVO and intracranial LAA is similar, despite the higher risk of stroke recurrence noted for those with LAA..$^{13,28}$ It is also important to recognize that a transient ischemic attack (TIA) calls for the same urgency in evaluation as a stroke. In one study, the risk of stroke after TIA was approximately $5 \%$ in the first 2 days and $10 \%$ within 90 days. $^{29}$ 

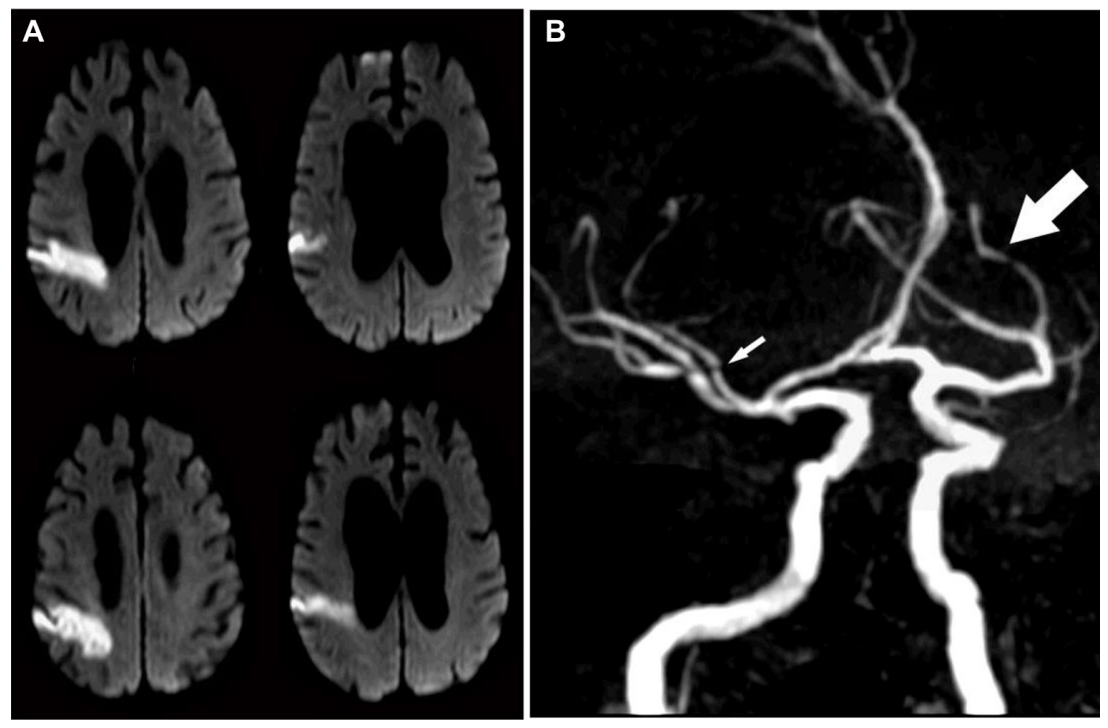

Figure 2 Stroke and intracranial atherosclerosis.

Notes: A woman in her 60s came to the hospital for left-sided weakness and headache. On exam, she was found to have mild left pronator drift and visuospatial neglect. (A) The brain magnetic resonance image showed evidence of a right parietal lobe cortical infarct and (B) the brain magnetic resonance angiograph showed evidence of diffuse luminal narrowing of her brain arteries (arrows), with some of these stenoses located proximal to the area of her infarction (small arrow), suggesting artery-to-artery embolism from intracranial large artery stenosis as the most likely stroke mechanism.
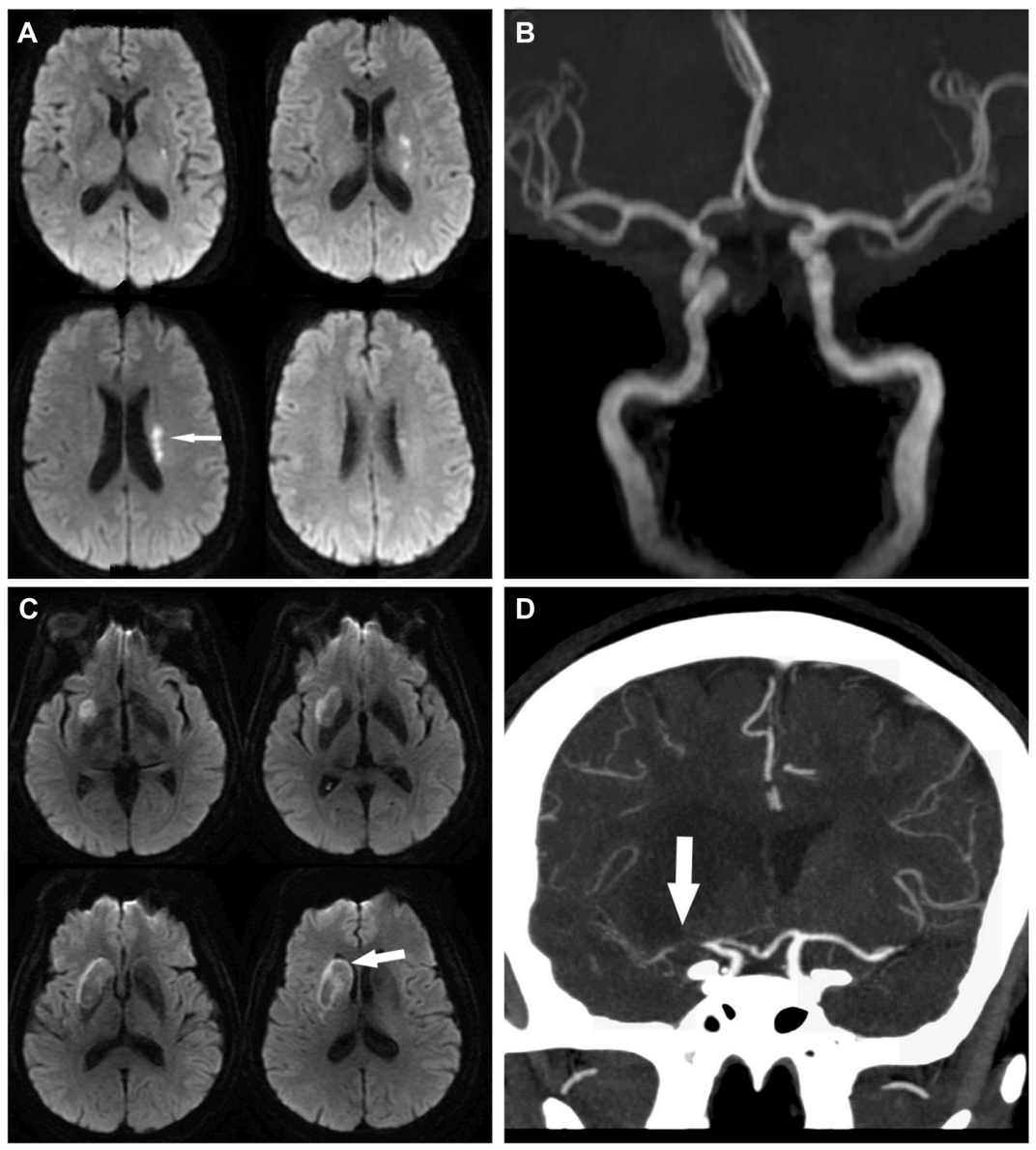

Figure 3 Small artery disease versus branch occlusive disease.

Notes: (A) An example of a small infarct in the left putamen and subcortical white matter (arrow), most likely due to the occlusion of a lenticulostriate artery branching of from the middle cerebral artery. (B) The brain magnetic resonance angiograph in this same patient showed no evidence of large artery stenosis in the proximal middle cerebral artery. (C) A patient with evidence of an infarct (arrow) involving the lenticular nucleus and the head of the caudate nucleus. (D) Contrary to the case presented in $\mathbf{A}$, this patient shows evidence of a high-degree of stenosis in the middle cerebral artery in the brain computed tomography angiograph (large arrow), suggesting branch occlusive disease and "pure" small artery disease as the underling etiology of the infarct. 


\section{General prevention strategies Antiplatelets}

As a group, antiplatelets offer an absolute risk reduction of $2 \%$ in vascular events per year, at the cost of a $0.1 \%-0.3 \%$ increase in major extracranial hemorrhages (Table 2). ${ }^{30,31}$ Aspirin is the most extensively studied, cheapest, and most commonly used agent in secondary stroke prevention. The US Food and Drug Administration currently recommends doses between 50 and $325 \mathrm{mg}$ daily for stroke prevention. ${ }^{6}$ There is no evidence that clopidogrel is superior to aspirin alone for secondary stroke prevention, but clopidogrel seems superior to aspirin in preventing combined vascular outcomes, which is mostly driven by a reduction in leg amputation among patients with peripheral arterial disease. ${ }^{32}$ Aspirin with extended-release dipyridamole, compared to aspirin alone, produced an approximate annual absolute risk reduction of $1 \%$ in two large clinical trials. ${ }^{33,34}$ Twice-a-day dosing and headache are drawbacks of aspirin with extended-release dipyridamole. On the other hand, a clinical trial investigating the use of clopidogrel vs the combination of aspirin with extended-release dipyridamole failed to show any significant reduction in events that would favor either agent. ${ }^{35}$
The choice of antiplatelet agents depends on the setting, the patient-specific comorbidities, and the patient's access to health care. While the low cost of, and extensive experience with, aspirin make it the leading choice in most cases, clopidogrel and aspirin with extended-release dipyridamole are reasonable alternatives as first-line therapy in those who have suffered a stroke.

\section{Hypertension}

Targeting hypertension carries the highest benefit in reducing stroke burden on a population level. ${ }^{3,36}$ The Perindopril Protection Against Recurrent Stroke Study (PROGRESS) trial was a randomized, double-blind, placebo-controlled trial of antihypertensive therapy among 6,105 patients with a history of hemorrhagic or ischemic stroke or TIA. Patients were treated with the angiotensin-converting enzyme inhibitor perindopril, with or without the addition of the thiazide diuretic indapamide. Therapy led to a mean blood pressure reduction of $9 / 4 \mathrm{mmHg}$ and a $4 \%$ absolute risk reduction in recurrent stroke, with similar reductions in patients with and without a history of hypertension. ${ }^{37}$ The Secondary Prevention of Small Subcortical Strokes (SPS3) trial, aside from

Table 2 Summary of some of the major studies comparing antiplatelets against each other or against placebo in stroke prevention

\begin{tabular}{|c|c|c|c|c|c|c|c|}
\hline $\begin{array}{l}\text { Secondary stroke } \\
\text { prevention setting }\end{array}$ & Trial & Placebo & ASA & ASA+D & C & ASA+C & Results \\
\hline \multirow[t]{3}{*}{ Acute (0-2 weeks) } & CAST $^{95}$ & + & + & & & & $\begin{array}{l}\text { I } 2 \% \text { RRR with ASA at } 4 \text { weeks with an ARR of } 0.6 \% \text { in early } \\
\text { mortality and nonfatal stroke }\end{array}$ \\
\hline & $\mathrm{IST}^{96}$ & + & + & & & & $\begin{array}{l}20 \% \text { RRR with ASA at } 2 \text { weeks with an ARR of } 0.9 \% \text { in stroke } \\
\text { recurrence }\end{array}$ \\
\hline & CHANCE $^{91}$ & & + & & & + & $\begin{array}{l}32 \% \text { RRR with dual antiplatelets in stroke with an ARR of } \\
3.5 \% \text { over } 3 \text { months in stroke }\end{array}$ \\
\hline Subacute & UKA TIA 100 & + & + & & & & I8\% RRR with ASA in composite outcome \\
\hline \multirow[t]{6}{*}{ (3-6 months) } & ESPS $^{94}$ & + & & + & & & $\begin{array}{l}38 \% \text { RRR with ASA+D in stroke recurrence with a yearly ARR } \\
\text { of } 2.5 \%\end{array}$ \\
\hline & ESPS2 ${ }^{99}$ & + & + & + & & & $\begin{array}{l}\text { I8\% RRR in ASA group compared to placebo } \\
37 \% \text { RRR in ASA+D with a yearly ARR of } 2.5 \% \text { in stroke/death } \\
\text { compared to placebo }\end{array}$ \\
\hline & ESPIRIT101 & & + & + & & & $\begin{array}{l}20 \% \text { RRR with ASA+D over ASA alone with a yearly ARR of } \\
1 \% \text { in composite outcome }\end{array}$ \\
\hline & PRoFESS 35 & & & + & + & & No difference in stroke recurrence \\
\hline & SPS3 ${ }^{28}$ & & + & & & + & $\begin{array}{l}\text { No benefit in stroke but increased risk of major hemorrhage } \\
\text { with dual antiplatelets ( } 2.1 \% \text { vs I.I\% per year) and increased } \\
\text { mortality ( } 2.1 \% \text { vs } 1.5 \% \text { per year) }\end{array}$ \\
\hline & CAPRIE $^{32}$ & & + & & + & & $\begin{array}{l}8.7 \% \text { RRR of C over ASA in all groups with a yearly ARR of } \\
0.5 \text { in composite outcome (driven by PVD group) }\end{array}$ \\
\hline & $\mathrm{AICLA}^{97}$ & + & + & + & & & $\begin{array}{l}40 \% \text { RRR in both groups as compared to placebo with a yearly } \\
\text { ARR of } 2 \% \text { in stroke }\end{array}$ \\
\hline (>3 months) & $\mathrm{MATCH}^{98}$ & & & & + & + & $\begin{array}{l}6.4 \% \text { RRR with dual antiplatelets in composite outcome, } \\
\text { countered by an increase in life-threatening bleeds ( } 2 \% \text { vs } 1 \%)\end{array}$ \\
\hline
\end{tabular}

Note: Although antiplatelets are frequently prescribed for preventing non-cardioembolic strokes, the relatively low risk reduction in all trials underscores the need to target other risk factors that may increase stroke recurrence. + signifies that the agent was studied in the trial.

Abbreviations: ARR, absolute risk reduction; ASA, aspirin; ASA+D, aspirin plus dipyridamole; C, clopidogrel; PVD, peripheral vascular disease; RRR, relative risk reduction; $A S A+C$, aspirin plus clopidogrel. 
studying the effect of dual-antiplatelet therapy, also examined the role of strict vs standard blood pressure management (systolic $<130 \mathrm{mmHg}$ vs $130-149 \mathrm{mmHg}$ ) on the outcome of stroke recurrence and showed a trend toward benefit in stroke recurrence in the lower blood pressure group. ${ }^{38} \mathrm{Cur}-$ rent American Heart Association guidelines recommend blood pressure goals of $<140 \mathrm{mmHg}$ and diastolic $<90$ $\mathrm{mmHg}$; however, there is evidence that the benefit of lowering blood pressure extends to levels far below this cutoff, and as suggested in the PROGRESS trial, treatment should not be reserved for only those with history of hypertension. ${ }^{6,39}$

\section{Hyperlipidemia}

Hypercholesterolemia is another general target in secondary stroke prevention. The Stroke Prevention by Aggressive Reduction in Cholesterol Levels (SPARCL) trial provided evidence of the benefit of statin therapy among patients with a TIA or stroke within the previous 6 months and no evidence of possible cardioembolic source (eg, atrial fibrillation). ${ }^{40}$ It enrolled 4,731 patients with a baseline low-density lipoprotein cholesterol level between 100 and $190 \mathrm{mg} / \mathrm{dL}$. Over a period of nearly 5 years, atorvastatin reduced the 5-year risk of recurrent stroke, from $13.1 \%$ to $11.2 \%$. Although participants who took atorvastatin had a higher incidence of hemorrhagic stroke, there were no differences in mortality compared to placebo. There was also no difference seen in the efficacy of atorvastatin based on stroke mechanism. ${ }^{41}$ As a result, statins have become the mainstay in lipid reduction therapy after a stroke or TIA.

\section{Diabetes}

Diabetes is one of the most important vascular risk factors for stroke and a high-yield target for preventive measures. Among patients with diabetes, the risk of vascular events is increased thrice compared to nondiabetics, and in combinations with other risk factors, the risk increases exponentially compared to individuals with those risk factors without diabetes. ${ }^{42}$ Intensive glycemic control (defined as glycated hemoglobin $<7 \%$ ) was not associated with a significant reduction in the rates of stroke (fatal or nonfatal) among patients with diabetes, although there was a reduction of $16 \%$ in a combined vascular outcome. ${ }^{33} \mathrm{~A}$ recent meta-analysis of clinical trials comparing intensive glycemic control vs standard glycemic controls demonstrated a non-statistically significant $7 \%$ risk reduction among those in the intensive care group. ${ }^{34}$ An early, aggressive control of glycemia has lasting benefits in vascular events in patients with type I diabetes, and the long-term favorable results of intensive glucose lowering among those with type II diabetes argues for an early recognition of diabetes as the most effective way to reduce the risk of vascular events and stroke. ${ }^{43,44}$ Patients with diabetes frequently have other vascular risk factors that should be aggressively controlled. For example, selected patients with diabetes (ie, young patients) should have a blood pressure target of $<130 / 80 \mathrm{mmHg}$ if tolerated. ${ }^{45}$

\section{Lifestyle modification}

Apart from pharmacological therapy, lifestyle modification, including a healthy diet, regular physical activity, and weight loss in overweight or obese patients, may have substantial benefits on blood pressure and lipid levels and, ultimately, stroke recurrence. Diet is probably the best studied when it comes to stroke prevention and the Mediterranean diet has been shown to protect against cardiovascular disease and specifically stroke, decreasing 5 -year stroke risk by approximately $30 \% .{ }^{46}$ In general, a diet that encourages a high intake of plant-based nutrients, low salt intake, and a limited intake of saturated fats and simple sugars is likely to have significant cardiovascular benefits if adhered to for a long period of time. Tobacco use should be strongly discouraged and among smokers, smoking cessation leads to a significant reduction in stroke risk. ${ }^{47}$ Furthermore, obesity is an independent risk factor for stroke, even after adjusting for physical activity and diet. ${ }^{4}$ Behavioral risk factors may be the most difficult to control, making patient education and a multidisciplinary approach extremely important.

\section{Secondary stroke prevention by specific mechanisms Cardioembolism}

\section{Atrial fibrillation}

The biggest modifier of stroke risk in persons with atrial fibrillation is anticoagulation (Table 3). When atrial fibrillation from a non-valvular cause is discovered, long-term stroke risk can be quantified using the CHADS2 or CHADS2-VASc prediction scoring systems, with $\mathrm{CHA}_{2} \mathrm{DS}_{2}$-VASc being preferred in recent American and European guidelines. ${ }^{48-50}$ Included in both scores are age $>75$ years, history of congestive heart failure, hypertension, diabetes mellitus, and previous stroke. The sole presence of one risk factor (other than history of stroke) places the patient at a low risk of systemic cardioembolism, while an annual stroke risk of $>1 \%$ based on the $\mathrm{CHA}_{2} \mathrm{DS}_{2}$-VASc score is typically considered the threshold to discuss the initiation of anticoagulation. This must be weighed against the risk of bleeding associated with anticoagulation. 
Table 3 Stroke mechanism and the estimated risk of stroke recurrence in the setting of prevention therapy

\begin{tabular}{|c|c|c|c|c|c|}
\hline $\begin{array}{l}\text { Stroke } \\
\text { mechanism }\end{array}$ & $\begin{array}{l}\text { Selected } \\
\text { trials }\end{array}$ & $\begin{array}{l}\text { Placebo/gold } \\
\text { standard }\end{array}$ & Treatment & Outcome(s) & Results \\
\hline \multirow[t]{2}{*}{ Carotid stenosis } & NASCET $^{81}$ & Best medical & CEA* & Stroke or death & $\begin{array}{l}\text { ARR of I } 0 \%(6 \% \text { vs } 16 \%) \text { with CEA vs best medical } \\
\text { management at I year in patients with severe stenosis }\end{array}$ \\
\hline & CREST $T^{14}$ & CEA & CAS & Stroke, MI, death & $\begin{array}{l}\text { Composite outcome for CAS }(7.2 \%) \text { is non-inferior to CEA } \\
(6.8 \%) \text { at } 4 \text { years }\end{array}$ \\
\hline \multirow[t]{2}{*}{$\begin{array}{l}\text { Intracranial } \\
\text { artery stenosis }\end{array}$} & WASID $^{13}$ & Aspirin & Warfarin & Stroke or death & $\begin{array}{l}\text { ARI of } 2 \% \text { ( } 17 \% \text { vs } 15 \% \text { ) with warfarin compared to aspirin } \\
\text { in patients with } 50 \%-99 \% \text { intracranial vessel stenosis }\end{array}$ \\
\hline & SAMMPRIS $^{90}$ & $\begin{array}{l}\text { Medical } \\
\text { therapy }\end{array}$ & $\begin{array}{l}\text { Angioplasty } \\
\text { and stenting }\end{array}$ & Ischemic stroke & $\begin{array}{l}\text { ARI of } 8 \%(20 \% \text { vs } 12 \%) \text { with angioplasty/stenting compared } \\
\text { to best medical practice alone in stenosis }>70 \%\end{array}$ \\
\hline Cardioembolic & EAFT $^{102}$ & $\begin{array}{l}\text { Placebo/ } \\
\text { Aspirin }\end{array}$ & Warfarin & $\begin{array}{l}\text { Stroke, death, MI, } \\
\text { systemic embolism }\end{array}$ & $\begin{array}{l}\text { ARR of } 9 \%(8 \% \text { vs } 17 \%) \text { with warfarin compared to } \\
\text { placebo/aspirin }\end{array}$ \\
\hline \multirow[t]{5}{*}{ Atrial fibrillation } & EAFT 102 & Placebo & Aspirin & & ARR of $4 \%$ ( $15 \%$ vs $19 \%$ ) with aspirin compared to placebo \\
\hline & RE-LY ${ }^{51}$ & & Dabigatran & & I. $27 \%$ vs $1.6 \%$ per year favoring NOAC \\
\hline & ROCKET AF ${ }^{53}$ & Warfarin & Rivaroxaban & $\begin{array}{l}\text { Stroke or systemic } \\
\text { embolism }\end{array}$ & I.11\% vs $1.71 \%$ per year favoring NOAC \\
\hline & ARISTOTLE ${ }^{52}$ & & Apixaban & & $2.1 \%$ vs $2.4 \%$ per year favoring NOAC \\
\hline & ENGAGE AF ${ }^{54}$ & & Edoxaban & & I.I8\% vs $1.5 \%$ per year favoring NOAC \\
\hline Heart failure & WARCEF $^{16}$ & Aspirin & Warfarin & Death or stroke & $\begin{array}{l}\text { No difference }(7.5 \% \text { vs } 7.9 \%) \text { in event rate between } \\
\text { warfarin and aspirin in patients with } \mathrm{CHF} \text { and } \mathrm{EF} \text { of }<35 \%\end{array}$ \\
\hline \multirow[t]{2}{*}{ Lacunar } & $\mathrm{SPS}^{23}$ & Aspirin & $\begin{array}{l}\text { Aspirin }+ \\
\text { clopidogrel }\end{array}$ & Stroke & $\begin{array}{l}\text { No difference in yearly risk ( } 2.7 \% \text { vs } 2.5 \%) \text { of single vs dual- } \\
\text { antiplatelet therapy in stroke incidence but increased risk } \\
\text { of complications with dual-antiplatelet therapy }\end{array}$ \\
\hline & CHANCE'I & Aspirin & $\begin{array}{l}\text { Aspirin }+ \\
\text { clopidogrel* }\end{array}$ & Stroke & $\begin{array}{l}\text { ARR of } 3.5 \%(8.2 \% \text { vs } 11.7 \%) \text { with dual antiplatelets } \\
\text { compared to a single antiplatelet agent, over } 3 \text { months }\end{array}$ \\
\hline
\end{tabular}

Notes: The stroke recurrence rates vary by stroke mechanism, thus the need to investigate for a plausible cause of stroke. The natural history of the disease is modified with various therapies as shown in this table. Large artery atherosclerosis, intra- and extracranial, confers one of the highest risks of stroke recurrence, thus the need to intensively look for it. Atrial fibrillation, sometimes elusive, may be identified with prolonged cardiac monitoring after the acute phase of stroke. Given the dramatic change in treatment if atrial fibrillation is found, ruling out this arrhythmia is one of the most important steps in deciding the adequate treatment for stroke prevention. "Stroke" refers to both ischemic and hemorrhagic unless otherwise specified. *Unlike the SPS3 trial, dual-antiplatelet therapy in CHANCE was initiated within 24 hours of symptoms onset. Abbreviations: $\mathrm{ARI}$, absolute risk increase; $\mathrm{ARR}$, absolute risk reduction; $\mathrm{CAS}$, carotid artery stenting; CEA, carotid endarterectomy; $\mathrm{CHF}$, chronic heart failure; $\mathrm{EF}$, ejection fraction; MI, myocardial infarction; NOAC, novel oral anticoagulant; RRR, relative risk reduction.

When used for stroke prevention from atrial fibrillation, warfarin is associated with a $60 \%-70 \%$ relative risk reduction in stroke and has been the gold standard in primary and secondary stroke prevention in patients with known persistent or paroxysmal atrial fibrillation. ${ }^{15}$ More recently, a set of novel oral anticoagulants (NOACs) have been approved specifically for thromboembolism prophylaxis in patients with non-valvular atrial fibrillation. When directly compared to warfarin in large randomized clinical trials, NOACs showed similar efficacy in preventing ischemic stroke and a relatively lower risk of intracranial hemorrhage (ICH) compared to warfarin. $^{51-54}$

Currently, there are four NOACs approved for prevention of stroke. They fall into the categories of either direct thrombin inhibitors or factor Xa inhibitors. They are dabigatran, rivaroxaban, apixaban, and edoxaban. Although their relative ease of use and lack of need for routine blood checks have made them popular first-line choices among some, the challenge and current-day dilemmas lie in the lack of monitoring assays, the lack of antidote, and the pricing, particularly for developing countries. There are, however, candidates on the horizon for an assay that can quickly and reliably track level of anticoagulation. ${ }^{55}$ This may be especially important in those with renal impairment, which has been shown to increase the risk of hemorrhagic complications with some of these agents. ${ }^{55}$

The lack of an antidote to reverse the therapeutic effects of the NOACs may be offset by lesser risk of ICH compared to warfarin. ${ }^{56}$ Further, individualized risk of in-hospital mortality from ICH was studied in a retrospective analysis, and no difference in outcome was seen in patients experiencing ICH secondary to warfarin compared to in patients who had been on dabigatran. ${ }^{57}$ This suggests that the lack of an antidote should not dissuade physicians from using dabigatran (and presumably any of the other NOACs) over warfarin. Currently, PER977 - small synthetic cationic molecule - is being investigated as a possible antidote to all of the NOACs alike. ${ }^{58}$

The greatest challenge in the prophylactic use of anticoagulation in the setting of atrial fibrillation revolves 
around the risk of ICH vs the benefit of preventing ischemic stroke. ${ }^{59}$ The HAS-BLED (Hypertension, Abnormal renal/ liver function, Stroke, Bleeding history or predisposition, Labile international normalized ratio, Elderly [ $>65$ years], Drugs/alcohol concomitantly) and ATRIA (Anticoagulation and Risk Factors in Atrial Fibrillation) prediction scoring systems are clinical decision-making tools that can aid the clinician in quantifying risk of hemorrhage, which can then be compared to yearly risk of stroke using CHADS2-VASc, to guide the clinician in how to best proceed. ${ }^{60,61}$

Until recently, patients with a high risk of bleeding had to be placed on less protective agents like aspirin, clopidogrel, or a combination of the two, as opposed to standard therapy with anticoagulation. In March 2015, the WATCHMANTM Left Atrial Appendage Closure Device was approved for use in the USA for the treatment of atrial fibrillation based on two trials showing non-inferiority to warfarin. ${ }^{62,63}$ Currently, the procedure is being offered to patients who carry a significant hemorrhagic risk with anticoagulation or have other contraindications to anticoagulation therapy. The caveat with using WATCHMAN is that patients need to be able to tolerate warfarin plus aspirin for at least 45 days (discontinued after there is proof of closure of the left atrial appendage) and dual antiplatelets for at least 6 months, which presents a challenge to the applicability of the WATCHMAN device to the FDAapproved high-risk population. ${ }^{63}$

\section{Prosthetic cardiac valves}

The risk of major embolism among patients with mechanical valves is estimated to be $4 \%$ per year without antithrombotic or anticoagulation therapy, $2 \%$ with the use of aspirin, and $1 \%$ with the use of anticoagulation. ${ }^{64}$ Anticoagulation with warfarin and occasionally with the additional low-dose aspirin (depending on comorbidities) is therefore indicated in patients with mechanical valves. ${ }^{65}$ Among patients with mechanical valves, NOACs are contraindicated. ${ }^{66}$ In patients with bioprosthetic valves, the risk of embolism is less compared to in those with mechanical valves, and a single antiplatelet is usually recommended for secondary stroke prophylaxis, although a short course of anticoagulation after implantation may be reasonable. ${ }^{65,67}$

\section{Low ejection fraction}

After an anterior wall MI, a third of patients develop a thrombus and a third of these have embolization. ${ }^{6}$ Predictors of left ventricular thrombus are low ejection fraction (EF), worsening EF after discharge, and wall dyskinesis. ${ }^{69}$ The most consistent predictor of embolization is thrombus mobility. ${ }^{68,69}$
It is considered reasonable to use short-term anticoagulation in patients with $\mathrm{MI}$ and evidence of left ventricular thrombus and in those with wall dyskinesis, but randomized data to universally recommend this intervention are lacking. ${ }^{70}$

Anticoagulation with warfarin in patients with dilated cardiomyopathy with an EF $<35 \%$ and a sinus rhythm was studied in one large trial warfarin and aspirin in patients with heart failure and sinus rhythm (WARCEF) and while the warfarin group had a lower incidence of ischemic stroke, any benefit was offset by an overall increase in major hemorrhage. ${ }^{16}$ Among WARCEF participants $<60$ years old, however, there was a benefit with anticoagulation vs aspirin, even after taking into account the rates of bleeding. ${ }^{71}$ In further subgroup analysis, those with prior stroke and an EF $<15 \%$ had a stroke risk of $6 \%$ per year, suggesting that in this high-risk group, the preventive effects of warfarin may offset the risk of hemorrhage. ${ }^{72}$ As a result, warfarin is currently not indicated for the sole purpose of stroke prevention in dilated cardiomyopathy with low EF and its use in some of the mentioned subgroups should be carefully discussed with the patients and their families.

\section{Aortic atheroma}

Complex aortic arch plaques, defined by a protruding component $>4 \mathrm{~mm}$, presence of a mobile component, or intraplaque ulceration, are deemed high risk for embolization. ${ }^{73}$ The 2-year risk of stroke or death among individuals with aortic plaques $<4 \mathrm{~mm}$ was $16.5 \%$ compared to $26.7 \%$ in those with plaques $\geq 4 \mathrm{~mm} .{ }^{74}$ In this observational study, the rate of events was similar among those using antiplatelets or warfarin. Whether anticoagulation reduces incident vascular events compared to antiplatelets in patients with aortic plaques $>4 \mathrm{~mm}$ has been formally explored in a clinical trial. ${ }^{75}$ The primary endpoint (cerebral infarction, MI, peripheral embolism, vascular death, or $\mathrm{ICH}$ ) in the group on anticoagulation occurred in $11.0 \%$ vs $7.6 \%$ in the dual-antiplatelet group, failing to reach statistical significance (probably due to the low rate of events). Further, the group on anticoagulation had a higher incidence of vascular death and $\mathrm{ICH}$. There is therefore no clear evidence to support the systematic use of anticoagulation in patients with aortic arch atheroma.

\section{Patent foramen ovale}

The role of anticoagulation among patients with possible paradoxical embolism through a patent foramen ovale (PFO) is unclear, and current guidelines support the use of antiplatelet agents for secondary prevention in this setting. ${ }^{76}$ 
Three large clinical trials have investigated whether closure of PFOs using trans-cardiac devices can reduce secondary stroke risk compared to medical therapy. None of them was able to show benefit of PFO closure when compared to medical therapy alone, in the intention-to-treat analysis. ${ }^{77-79}$ Importantly, the yearly rates of stroke differed among these trials. In the closure or medical therapy for cryptogenic stroke with patent foramen ovale (CLOSURE) I trial, the 2 -year rate of stroke recurrence was $7 \%$ in the medical group, while in the closure of patent foramen ovale versus medical therapy after cryptogenic stroke (RESPECT) and percutaneous closure of patent foramen ovale in cryptogenic embolism (PC) trials (with more stringent criteria for ruling out alternative stroke mechanisms), the rates were closer to $1 \%$ per year. This discrepancy is in itself a challenge to the interpretation of these trials, but suggests that in studies reporting a high rate of stroke recurrence attributed to a PFO, participants have alternative stoke mechanisms that are not modified by closing a PFO. Ideally, clinical trials assessing whether closing the PFO reduces the risk of stroke recurrence would benefit from using a probabilistic model like the RoPE (Risk of Paradoxical Embolism) score to identify those with the highest likelihood for a causal role of the PFO, after exhaustive workup to rule out alternative etiologies. ${ }^{80}$ Until stronger data exist to justify the use of a device to close the PFO and its potential risks, a single daily antiplatelet seems a reasonable recommendation in patients with truly cryptogenic strokes.

\section{Extracranial carotid atherosclerosis}

Extracranial carotid artery stenosis is most effectively treated with endarterectomy or stenting (Figure 1). There have been a number of studies comparing best medical management vs carotid endarterectomy (CEA) in patients with symptomatic carotid stenosis. The North American Symptomatic Carotid Endarterectomy Trial demonstrated a risk reduction of $17 \%$ in all ipsilateral stroke recurrence, and $11 \%$ in ipsilateral major or fatal strokes ${ }^{81}$ Post hoc analysis of this study demonstrated that the greatest value of CEA comes if the procedure is done within 2 weeks of the stroke. ${ }^{82}$ The European Carotid Surgery Trial showed a comparable risk reduction in the surgical arm for patients with carotid stenosis $>80 \%$. An analysis of pooled data for symptomatic carotid stenosis trials demonstrated robust beneficial effects of surgical interventions across trials in stenosis of $\geq 70 \%$, with more marginal effects with lesser degrees of stenosis or in those with carotid occlusion. ${ }^{83}$ Among patients with carotid occlusion and evidence of increased oxygen extraction in the ipsilateral hemisphere (ie, at the greatest risk of recurrent stroke), an extracranialintracranial arterial bypass failed to reduce the risk of stroke recurrence in one study. ${ }^{84}$

Three large trials have assessed whether carotid artery stenting (CAS) is as equally effective as CEA among patients with symptomatic extracranial carotid atherosclerosis..$^{14,85,86}$ The results consistently show a slight increase in periprocedural stroke (30 days) with CAS compared to CEA. Combined adverse outcomes over a 2-year period are similar, however, establishing CAS as a viable option for treating severe symptomatic carotid stenosis in high-risk surgical patients or those with unsuitable anatomy.

In patients with asymptomatic carotid stenosis, older evidence suggested a benefit in CEA vs medical therapy, but the effect size was more modest and the benefit delayed, compared to the benefit observed for patients with symptomatic carotid stenosis. ${ }^{87,88}$ Furthermore, the advent of statins and more aggressive medical therapy may have reduced the differential effects of surgical intervention compared to modern medical therapy. Based on this presumed medical equipoise, a new trial will investigate the effect modification of CEA or carotid stenting against medical therapy in patients with asymptomatic carotid stenosis. ${ }^{89}$

\section{Intracranial LAA}

Several trials have investigated the best possible treatment in stroke recurrence in the setting of intracranial vessel stenosis (Figure 2). The Warfarin and Aspirin Symptomatic Intracranial Disease (WASID) trial studied aspirin vs warfarin in patients with verified 50\%-99\% stenosis of a major intracranial artery (carotid, middle cerebral, vertebral, or basilar arteries).${ }^{13}$ Even though the study was stopped early because of the high rate of adverse events in the warfarin group, it showed a 20\% 2-year risk of overall stroke recurrence and a $15 \%$ 2-year risk of stroke recurrence in the vascular territory distal to the stenosis. ${ }^{13}$

To directly address this high-risk group of patients, the Stenting and Aggressive Medical Management for Preventing Recurrent Stroke in Intracranial Stenosis (SAMMPRIS) trial attempted to follow the therapeutic model used in coronary artery disease by comparing percutaneous transluminal angioplasty and stenting to best medical therapy in patients with recent stroke and proximal intracranial arterial stenosis of $>70 \% .{ }^{90}$ Both groups received aggressive lifestyle modification counseling and intervention and were placed on dual-antiplatelet therapy with aspirin and clopidogrel for 3 months. The final outcome of stroke or death occurred in $20 \%$ in the stenting group and $12 \%$ in the medical group at 
1 year. The majority of strokes in the intervention arm were perioperative, occurring in the first 30 days. Although a recurrence of $12 \%$ per year among those with medical therapy is intolerably high, aggressive medical therapy appears to be the only proven therapy recommended for patients with intracranial LAA. Novel therapies are evidently and urgently needed to further reduce the risk of stroke recurrence among this population.

\section{Small artery occlusion/lacunar stroke}

Antiplatelet therapy with clopidogrel and aspirin, compared to aspirin alone, was investigated as secondary prevention after lacunar stroke in the SPS3 trial. ${ }^{28}$ There was no evidence of a reduction in the rates of recurrent strokes using dual antiplatelets vs aspirin alone (2.5\% vs $2.7 \%$ per year), but an increase in the risk of bleeding and mortality was noted in the dual-antiplatelet therapy group. Based on this, there is no evidence to support the use of dual antiplatelets to reduce the risk of recurrent stroke in the long-term.

In the short-term, however, there may be a role for the use of dual antiplatelets in "minor" strokes or TIA. The Clopidogrel in High-risk Patients with Acute Non-disabling Cerebrovascular Events (CHANCE) trial found that a 21-day course of dual-antiplatelet therapy with aspirin and clopidogrel among Chinese patients with TIA and minor stroke, given within 24 hours of symptom onset, lowered the 3-month stroke recurrence rate. ${ }^{91}$ The majority of the benefit from dualantiplatelet therapy in CHANCE occurred within the first week of treatment. A short course of aspirin and clopidogrel in the early period may therefore be considered, but whether these results are applicable to non-Chinese populations will be further investigated in the Platelet-Oriented Inhibition in New TIA (POINT) trial. ${ }^{22}$

\section{Future directions/Conclusion}

Preventing stroke recurrence is one of the major concerns of practitioners who treat patients with stroke, either in the hospital or in the clinic. Determining the potential causal mechanisms of a patient's stroke offers the opportunity to establish tailored therapies, while in the hospital or shortly after, for extracranial carotid stenosis, intracranial large artery stenosis with flow failure, cardiac thrombus in the setting of low EF and/or atrial fibrillation. Defining stroke mechanism, however, is challenging and, as discussed, it is crucial that physicians exhaustively rule out alternative etiologies for stroke. In the case of mixed etiologies (eg, intracranial atherosclerosis in patient with atrial fibrillation), the proven treatment for the conditions with the highest risk of recurrence might be indicated. A comprehensive stroke workup is expensive, and it may not be within reach in developing countries where stroke represents an even greater challenge. Developing cheaper methods to more accurately ascertain stroke mechanism may be a way to overcome this challenge.

Furthermore, although clinical trials have framed and keep fine-tuning the major therapeutic axis for stroke prevention, there are still many uncertainties in specific conditions with higher risk of stroke. These less frequent, and consequently less well-studied, conditions or clinical scenarios lead to heterogeneous patterns of practice that may result in more expensive treatment or even worse - harm to patients. Collaborations across major academic centers and integrated electronic systems may offer an opportunity to study outcomes in some of these cases, which may lead to a more unified and better informed approach to treat patients with stroke.

Finally, in our view, the greatest challenge is that, even with the best medical therapies, the recurrence rates of stroke are not zero, and one out of four patients who have had strokes in the USA has a recurrent event. It is imperative to foster the development of newer therapies to reduce even further the risk of stroke recurrence. Given the unacceptably high risk of stroke recurrence with traditional vascular disease, a stronger effort is needed in controlling vascular risk factor on a population-based level.

\section{Disclosure}

The authors report no conflicts of interest in this work.

\section{References}

1. Sacco RL, Kasner SE, Broderick JP, et al; American Heart Association Stroke Council, Council on Cardiovascular Surgery and Anesthesia; Council on Cardiovascular Radiology and Intervention; Council on Cardiovascular and Stroke Nursing; et al. An updated definition of stroke for the 21 st century: a statement for healthcare professionals from the American Heart Association/American Stroke Association. Stroke. 2013;44(7):2064-2089.

2. Mozaffarian D, Benjamin EJ, Go AS, et al; American Heart Association Statistics Committee and Stroke Statistics Subcommittee. Heart disease and stroke statistics - 2015 update: a report from the American Heart Association. Circulation. 2015;131(4):e29-e322.

3. O'Donnell MJ, Xavier D, Liu L, et al; INTERSTROKE investigators. Risk factors for ischaemic and intracerebral haemorrhagic stroke in 22 countries (the INTERSTROKE study): a case-control study. Lancet. 2010;376(9735):112-123.

4. Lackland DT, Roccella EJ, Deutsch AF, et al; American Heart Association Stroke Council; Council on Cardiovascular and Stroke Nursing; Council on Quality of Care and Outcomes Research; Council on Functional Genomics and Translational Biology. Factors influencing the decline in stroke mortality: a statement from the American Heart Association/American Stroke Association. Stroke. 2014;45(1): 315-353.

5. Bamford J, Sandercock P, Dennis M, Burn J, Warlow C. Classification and natural history of clinically identifiable subtypes of cerebral infarction. Lancet. 1991;337(8756):1521-1526. 
6. Kernan WN, Ovbiagele B, Black HR, et al; American Heart Association Stroke Council, Council on Cardiovascular and Stroke Nursing, Council on Clinical Cardiology, and Council on Peripheral Vascular Disease. Guidelines for the prevention of stroke in patients with stroke and transient ischemic attack: a guideline for healthcare professionals from the American Heart Association/American Stroke Association. Stroke. 2014;45(7):2160-2236.

7. Adams HP Jr, Bendixen BH, Kappelle LJ, et al. Classification of subtype of acute ischemic stroke. Definitions for use in a multicenter clinical trial. TOAST. Trial of Org 10172 in Acute Stroke Treatment. Stroke. 1993;24(1):35-41.

8. Ay H, Furie KL, Singhal A, Smith WS, Sorensen AG, Koroshetz WJ. An evidence-based causative classification system for acute ischemic stroke. Ann Neurol. 2005;58(5):688-697.

9. Ay H, Benner T, Arsava EM, et al. A computerized algorithm for etiologic classification of ischemic stroke: the Causative Classification of Stroke System. Stroke. 2007;38(11):2979-2984.

10. Gutierrez J, Koch S, Dong C, et al. Racial and ethnic disparities in stroke subtypes: a multiethnic sample of patients with stroke. Neurol Sci. 2014;35(4):877-582.

11. Schneider AT, Kissela B, Woo D, et al. Ischemic stroke subtypes: a population-based study of incidence rates among blacks and whites. Stroke. 2004;35(7):1552-1556.

12. Atherosclerotic disease of the aortic arch as a risk factor for recurrent ischemic stroke. The French Study of Aortic Plaques in Stroke Group. N Engl J Med. 1996;334(19):1216-1221.

13. Chimowitz MI, Lynn MJ, Howlett-Smith H, et al; Warfarin-Aspirin Symptomatic Intracranial Disease Trial Investigators. Comparison of warfarin and aspirin for symptomatic intracranial arterial stenosis. N Engl J Med. 2005;352(13):1305-1316.

14. Brott TG, Hobson RW 2nd, Howard G, et al; CREST Investigators. Stenting versus endarterectomy for treatment of carotid-artery stenosis. N Engl J Med. 2010;363(1):11-23.

15. Warfarin versus aspirin for prevention of thromboembolism in atrial fibrillation: Stroke Prevention in Atrial Fibrillation II Study. Lancet. 1994;343(8899):687-691.

16. Homma S, Thompson JL, Pullicino PM, et al; WARCEF Investigators. Warfarin and aspirin in patients with heart failure and sinus rhythm. N Engl J Med. 2012;366(20):1859-1869.

17. Jugdutt BI, Sivaram CA. Prospective two-dimensional echocardiographic evaluation of left ventricular thrombus and embolism after acute myocardial infarction. J Am Coll Cardiol. 1989;13(3): 554-564.

18. Petty GW, Khandheria BK, Whisnant JP, Sicks JD, O'Fallon WM, Wiebers DO. Predictors of cerebrovascular events and death among patients with valvular heart disease: a population-based study. Stroke. 2000;31(11):2628-2635.

19. Gan R, Sacco RL, Kargman DE, Roberts JK, Boden-Albala B, Gu Q. Testing the validity of the lacunar hypothesis: the Northern Manhattan Stroke Study experience. Neurology. 1997;48(5):1204-1211.

20. Fisher CM. Lacunar strokes and infarcts: a review. Neurology. 1982; 32(8):871-876.

21. Ritter MA, Kochhäuser S, Duning T, et al. Occult atrial fibrillation in cryptogenic stroke: detection by 7-day electrocardiogram versus implantable cardiac monitors. Stroke. 2013;44(5):1449-1452.

22. Sanna T, Diener HC, Passman RS, et al; CRYSTAL AF Investigators. Cryptogenic stroke and underlying atrial fibrillation. $N$ Engl J Med. 2014;370(26):2478-2486.

23. Favilla CG, Ingala E, Jara J, et al. Predictors of finding occult atrial fibrillation after cryptogenic stroke. Stroke. 2015;46(5): 1210-1215.

24. Arboix A, Martí-Vilalta JL. Lacunar stroke. Expert Rev Neurother. 2009;9(2):179-196.

25. Kasner SE, Chimowitz MI, Lynn MJ, et al; Warfarin Aspirin Symptomatic Intracranial Disease Trial Investigators. Predictors of ischemic stroke in the territory of a symptomatic intracranial arterial stenosis. Circulation. 2006;113(4):555-563.
26. Lavallée PC, Labreuche J, Faille D, et al; Lacunar-BICHAT Investigators. Circulating markers of endothelial dysfunction and platelet activation in patients with severe symptomatic cerebral small vessel disease. Cerebrovasc Dis. 2013;36(2):131-138.

27. Deplanque D, Lavallee PC, Labreuche J, et al; Lacunar-BICHAT Investigators. Cerebral and extracerebral vasoreactivity in symptomatic lacunar stroke patients: a case-control study. Int J Stroke. 2013;8(6):413-421.

28. SPS3 Investigators, Benavente OR, Hart RG, et al. Effects of clopidogrel added to aspirin in patients with recent lacunar stroke. $N$ Engl J Med. 2012;367(9):817-825.

29. Johnston SC, Sidney S, Bernstein AL, Gress DR. A comparison of risk factors for recurrent TIA and stroke in patients diagnosed with TIA. Neurology. 2003;60(2):280-285.

30. Antithrombotic Trialists' (ATT) Collaboration, Baigent C, Blackwell L, et al. Aspirin in the primary and secondary prevention of vascular disease: collaborative meta-analysis of individual participant data from randomised trials. Lancet. 2009;373(9678):1849-1860.

31. ATT Collaboration. Collaborative meta-analysis of randomised trials of antiplatelet therapy for prevention of death, myocardial infarction, and stroke in high risk patients. BMJ. 2002;324(7329): 71-86.

32. CAPRIE Steering Committee. A randomised, blinded, trial of clopidogrel versus aspirin in patients at risk of ischaemic events (CAPRIE). CAPRIE Steering Committee. Lancet. 1996;348(9038): 1329-1339.

33. Intensive blood-glucose control with sulphonylureas or insulin compared with conventional treatment and risk of complications in patients with type 2 diabetes (UKPDS 33). UK Prospective Diabetes Study (UKPDS) Group. Lancet. 1998;352(9131):837-853.

34. Ray KK, Seshasai SR, Wijesuriya S, et al. Effect of intensive control of glucose on cardiovascular outcomes and death in patients with diabetes mellitus: a meta-analysis of randomised controlled trials. Lancet. 2009;373(9677):1765-1772.

35. Sacco RL, Diener HC, Yusuf S, et al; PRoFESS Study Group. Aspirin and extended-release dipyridamole versus clopidogrel for recurrent stroke. N Engl J Med. 2008;359(12):1238-1251.

36. Willey JZ, Moon YP, Kahn E, et al. Population attributable risks of hypertension and diabetes for cardiovascular disease and stroke in the northern Manhattan study. J Am Heart Assoc. 2014;3(5): e001106

37. PROGRESS Collaborative Group. Randomised trial of a perindopril-based blood-pressure-lowering regimen among 6,105 individuals with previous stroke or transient ischaemic attack. Lancet. 2001;358(9287):1033-1041.

38. SPS3 Study Group, Benavente OR, Coffey CS, et al. Blood-pressure targets in patients with recent lacunar stroke: the SPS3 randomised trial. Lancet. 2013;382(9891):507-515.

39. Law MR, Morris JK, Wald NJ. Use of blood pressure lowering drugs in the prevention of cardiovascular disease: meta-analysis of 147 randomised trials in the context of expectations from prospective epidemiological studies. BMJ. 2009;338:b1665.

40. Amarenco P, Bogousslavsky J, Callahan A 3rd, et al; Stroke Prevention by Aggressive Reduction in Cholesterol Levels (SPARCL) Investigators. High-dose atorvastatin after stroke or transient ischemic attack. $N$ Engl $J$ Med. 2006;355(6):549-559.

41. Amarenco P, Benavente O, Goldstein LB, et al; Stroke Prevention by Aggressive Reduction in Cholesterol Levels Investigators. Results of the Stroke Prevention by Aggressive Reduction in Cholesterol Levels (SPARCL) trial by stroke subtypes. Stroke. 2009;40(4):1405-1409.

42. Stamler J, Vaccaro O, Neaton JD, Wentworth D. Diabetes, other risk factors, and 12-yr cardiovascular mortality for men screened in the Multiple Risk Factor Intervention Trial. Diabetes Care. 1993;16(2): 434-444.

43. Holman RR, Paul SK, Bethel MA, Matthews DR, Neil HA. 10-year follow-up of intensive glucose control in type 2 diabetes. $N$ Engl J Med. 2008;359(15):1577-1589. 
44. Diabetes Control and Complications Trial/Epidemiology of Diabetes Interventions and Complications (DCCT/EDIC) Research Group, Nathan DM, Zinman B, et al. Modern-day clinical course of type 1 diabetes mellitus after 30 years' duration: the diabetes control and complications trial/epidemiology of diabetes interventions and complications and Pittsburgh epidemiology of diabetes complications experience (1983-2005). Arch Intern Med. 2009;169(14):1307-1316.

45. Arauz-Pacheco C, Parrott MA, Raskin P; American Diabetes Association. Treatment of hypertension in adults with diabetes. Diabetes Care. 2003;26 Suppl 1:S80-S82.

46. Estruch R, Ros E, Martínez-González MA. Mediterranean diet for primary prevention of cardiovascular disease. $N$ Engl J Med. 2013; 369(7):676-677.

47. Wolf PA, D'Agostino RB, Kannel WB, Bonita R, Belanger AJ. Cigarette smoking as a risk factor for stroke. The Framingham Study. JAMA 1988;259(7):1025-1029.

48. Gage BF, Waterman AD, Shannon W, Boechler M, Rich MW, Radford MJ. Validation of clinical classification schemes for predicting stroke: results from the National Registry of Atrial Fibrillation. JAMA. 2001;285(22):2864-2870.

49. Lip GY, Nieuwlaat R, Pisters R, Lane DA, Crijns HJ. Refining clinical risk stratification for predicting stroke and thromboembolism in atrial fibrillation using a novel risk factor-based approach: the euro heart survey on atrial fibrillation. Chest. 2010;137(2):263-272.

50. Camm AJ, Lip GY, De Caterina R, et al; ESC Committee for Practice Guidelines-CPG; Document Reviewers. 2012 focused update of the ESC Guidelines for the management of atrial fibrillation: an update of the 2010 ESC Guidelines for the management of atrial fibrillation developed with the special contribution of the European Heart Rhythm Association. Europace. 2012;14(10):1385-1413.

51. Connolly SJ, Ezekowitz MD, Yusuf S, et al; RE-LY Steering Committee and Investigators. Dabigatran versus warfarin in patients with atrial fibrillation. N Engl J Med. 2009;361(12):1139-1151.

52. Granger CB, Alexander JH, McMurray JJ, et al; ARISTOTLE Committees and Investigators. Apixaban versus warfarin in patients with atrial fibrillation. N Engl J Med. 2011;365(11):981-992.

53. Patel MR, Mahaffey KW, Garg J, et al; ROCKET AF Investigators. Rivaroxaban versus warfarin in nonvalvular atrial fibrillation. $N$ Engl J Med. 2011;365(10):883-891.

54. Giugliano RP, Ruff CT, Braunwald E, et al; ENGAGE AF-TIMI 48 Investigators. Edoxaban versus warfarin in patients with atrial fibrillation. N Engl J Med. 2013;369(22):2093-2104.

55. Avecilla ST, Ferrell C, Chandler WL, Reyes M. Plasma-diluted thrombin time to measure dabigatran concentrations during dabigatran etexilate therapy. Am J Clin Pathol. 2012;137(4):572-574.

56. Miller CS, Grandi SM, Shimony A, Filion KB, Eisenberg MJ. Metaanalysis of efficacy and safety of new oral anticoagulants (dabigatran, rivaroxaban, apixaban) versus warfarin in patients with atrial fibrillation. Am J Cardiol. 2012;110(3):453-460.

57. Alonso A, Bengtson LG, MacLehose RF, Lutsey PL, Chen LY, Lakshminarayan $\mathrm{K}$. Intracranial hemorrhage mortality in atrial fibrillation patients treated with dabigatran or warfarin. Stroke. 2014;45(8):2286-2291.

58. Ansell JE, Bakhru SH, Laulicht BE, et al. Use of PER977 to reverse the anticoagulant effect of edoxaban. $N$ Engl J Med. 2014;371(22): 2141-2142.

59. Morgenstern LB, Hemphill JC 3rd, Anderson C, et al. Guidelines for the management of spontaneous intracerebral hemorrhage: a guideline for healthcare professionals from the American Heart Association/ American Stroke Association. Stroke. 2010;41(9):2108-2129.

60. Pisters R, Lane DA, Nieuwlaat R, de Vos CB, Crijns HJ, Lip GY. A novel user-friendly score (HAS-BLED) to assess 1-year risk of major bleeding in patients with atrial fibrillation: the Euro Heart Survey. Chest. 2010;138(5):1093-1100.

61. Singer DE, Chang Y, Borowsky LH, et al. A new risk scheme to predict ischemic stroke and other thromboembolism in atrial fibrillation: the ATRIA study stroke risk score. $J$ Am Heart Assoc. 2013;2(3): 000250 .
62. Reddy VY, Holmes D, Doshi SK, Neuzil P, Kar S. Safety of percutaneous left atrial appendage closure: results from the Watchman Left Atrial Appendage System for Embolic Protection in Patients with AF (PROTECT AF) clinical trial and the Continued Access Registry. Circulation. 2011;123(4):417-424.

63. Holmes DR Jr, Kar S, Price MJ, et al. Prospective randomized evaluation of the Watchman Left Atrial Appendage Closure device in patients with atrial fibrillation versus long-term warfarin therapy: the PREVAIL trial. J Am Coll Cardiol. 2014;64(1):1-12.

64. Cannegieter SC, Rosendaal FR, Briët E. Thromboembolic and bleeding complications in patients with mechanical heart valve prostheses. Circulation. 1994;89(2):635-641.

65. Nishimura RA, Otto CM, Bonow RO, et al. 2014 AHA/ACC guideline for the management of patients with valvular heart disease: a report of the American College of Cardiology/American Heart Association Task Force on Practice Guidelines. J Thorac Cardiovasc Surg. 2014;148(1): e1-e132.

66. Eikelboom JW, Connolly SJ, Brueckmann M, et al; RE-ALIGN Investigators. Dabigatran versus warfarin in patients with mechanical heart valves. N Engl J Med. 2013;369(13):1206-1214.

67. Brennan JM, Edwards FH, Zhao Y, et al; DEcIDE AVR (Developing Evidence to Inform Decisions about Effectiveness-Aortic Valve Replacement) Research Team. Long-term safety and effectiveness of mechanical versus biologic aortic valve prostheses in older patients: results from the Society of Thoracic Surgeons Adult Cardiac Surgery National Database. Circulation. 2013;127(16):1647-1655.

68. Johannessen KA, Nordrehaug JE, von der Lippe G, Vollset SE. Risk factors for embolisation in patients with left ventricular thrombi and acute myocardial infarction. Br Heart J. 1988;60(2):104-110.

69. Keren A, Goldberg S, Gottlieb S, et al. Natural history of left ventricular thrombi: their appearance and resolution in the posthospitalization period of acute myocardial infarction. J Am Coll Cardiol. 1990;15(4): $790-800$.

70. O'Gara PT, Kushner FG, Ascheim DD, et al; American College of Cardiology Foundation/American Heart Association Task Force on Practice Guidelines. 2013 ACCF/AHA guideline for the management of ST-elevation myocardial infarction: a report of the American College of Cardiology Foundation/American Heart Association Task Force on Practice Guidelines. Circulation. 2013;127(4):e362-e425.

71. Homma S, Thompson JL, Sanford AR, et al; WARCEF Investigators. Benefit of warfarin compared with aspirin in patients with heart failure in sinus rhythm: a subgroup analysis of WARCEF, a randomized controlled trial. Circ Heart Fail. 2013;6(5):988-997.

72. Pullicino PM, Qian M, Sacco RL, et al. Recurrent stroke in the warfarin versus aspirin in reduced cardiac ejection fraction (WARCEF) trial. Cerebrovasc Dis. 2014;38(3):176-181.

73. Meier B, Frank B, Wahl A, Diener HC. Secondary stroke prevention: patent foramen ovale, aortic plaque, and carotid stenosis. Eur Heart $J$. 2012;33(6):705-713, 713a, 713b.

74. Di Tullio MR, Russo C, Jin Z, Sacco RL, Mohr JP, Homma S; Patent Foramen Ovale in Cryptogenic Stroke Study Investigators. Aortic arch plaques and risk of recurrent stroke and death. Circulation. 2009; 119(17):2376-2382.

75. Amarenco P, Davis S, Jones EF, et al. Clopidogrel plus aspirin versus warfarin in patients with stroke and aortic arch plaques. Stroke. 2014; 45(5): 1248-1257.

76. Furie KL, Kasner SE, Adams RJ, et al; American Heart Association Stroke Council, Council on Cardiovascular Nursing, Council on Clinical Cardiology, Interdisciplinary Council on Quality of Care and Outcomes Research. Guidelines for the prevention of stroke in patients with stroke or transient ischemic attack: a guideline for healthcare professionals from the american heart association/american stroke association. Stroke. 2011;42(1):227-276

77. Carroll JD, Saver JL, Thaler DE, et al; RESPECT Investigators. Closure of patent foramen ovale versus medical therapy after cryptogenic stroke. N Engl J Med. 2013;368(12):1092-1100. 
78. Meier B, Kalesan B, Mattle HP, et al; PC Trial Investigators. Percutaneous closure of patent foramen ovale in cryptogenic embolism. N Engl J Med. 2013;368(12):1083-1091.

79. Furlan AJ, Reisman M, Massaro J, et al; CLOSURE I Investigators. Closure or medical therapy for cryptogenic stroke with patent foramen ovale. N Engl J Med. 2012;366(11):991-999.

80. Kent DM, Ruthazer R, Weimar C, et al. An index to identify strokerelated vs incidental patent foramen ovale in cryptogenic stroke. Neurology. 2013;81(7):619-625.

81. North American Symptomatic Carotid Endarterectomy Trial Collaborators. Beneficial effect of carotid endarterectomy in symptomatic patients with high-grade carotid stenosis. N Engl J Med. 1991; 325(7):445-453

82. Ferguson GG, Eliasziw M, Barr HW, et al. The North American Symptomatic Carotid Endarterectomy Trial: surgical results in 1415 patients. Stroke. 1999;30(9):1751-1758.

83. Rothwell PM, Eliasziw M, Gutnikov SA, et al; Carotid Endarterectomy Trialists' Collaboration. Analysis of pooled data from the randomised controlled trials of endarterectomy for symptomatic carotid stenosis. Lancet. 2003;361(9352):107-116.

84. Powers WJ, Clarke WR, Grubb RL Jr, Videen TO, Adams HP Jr, Derdeyn CP; COSS Investigators. Extracranial-intracranial bypass surgery for stroke prevention in hemodynamic cerebral ischemia: the Carotid Occlusion Surgery Study randomized trial. JAMA. 2011;306(18):1983-1992.

85. Eckstein HH, Ringleb P, Allenberg JR, et al. Results of the StentProtected Angioplasty versus Carotid Endarterectomy (SPACE) study to treat symptomatic stenoses at 2 years: a multinational, prospective, randomised trial. Lancet Neurol. 2008;7(10):893-902.

86. International Carotid Stenting Study Investigators, Ederle J, Dobson J, et al. Carotid artery stenting compared with endarterectomy in patients with symptomatic carotid stenosis (International Carotid Stenting Study): an interim analysis of a randomised controlled trial. Lancet. 2010;375(9719):985-997.

87. Endarterectomy for asymptomatic carotid artery stenosis. Executive Committee for the Asymptomatic Carotid Atherosclerosis Study. JAMA. 1995;273(18):1421-1428.

88. Halliday A, Mansfield A, Marro J, et al; MRC Asymptomatic Carotid Surgery Trial (ACST) Collaborative Group. Prevention of disabling and fatal strokes by successful carotid endarterectomy in patients without recent neurological symptoms: randomised controlled trial. Lancet. 2004;363(9420):1491-1502.

89. Brott TG. Carotid Revascularization and Medical Management for Asymptomatic Carotid Stenosis Trial (CREST-2). In: ClinicalTrials.gov [website on the Internet]. Bethseda, MD: US National Library of Medicine; 2014 [updated May 27, 2015]. Available from: https://clinicaltrials. gov/ct2/show/NCT02089217. NLM identifier: NCT02089217. Accessed April 14, 2015.
90. Derdeyn CP, Chimowitz MI, Lynn MJ, et al; Stenting and Aggressive Medical Management for Preventing Recurrent Stroke in Intracranial Stenosis Trial Investigators. Aggressive medical treatment with or without stenting in high-risk patients with intracranial artery stenosis (SAMMPRIS): the final results of a randomised trial. Lancet. 2014; 383(9914):333-341.

91. Wang Y, Wang Y, Zhao X, et al; CHANCE Investigators. Clopidogrel with aspirin in acute minor stroke or transient ischemic attack. $N$ Engl JMed. 2013;369(1):11-19.

92. Johnston SC, Easton JD, Farrant M, et al. Platelet-oriented inhibition in new TIA and minor ischemic stroke (POINT) trial: rationale and design. Int J Stroke. 2013;8(6):479-483.

93. Sevush-Garcy J, Gutierrez J. An epidemiological perspective on race/ ethnicity and stroke. Curr Cardiovasc Risk Rep. 2015;9:19.

94. [No authors listed]. The European Stroke Prevention Study (ESPS). Principal end-points. The ESPS Group. Lancet. 1987;2(8572):1351-1354.

95. [No authors listed]. CAST: randomised placebo-controlled trial of early aspirin use in 20,000 patients with acute ischaemic stroke. CAST (Chinese Acute Stroke Trial) Collaborative Group. Lancet. 1997;349(9066):1641-1649.

96. [No authors listed]. The International Stroke Trial (IST): a randomised trial of aspirin, subcutaneous heparin, both, or neither among 19435 patients with acute ischaemic stroke. International Stroke Trial Collaborative Group. Lancet. 1997;349(9065):1569-1581.

97. Bousser MG, Eschwege E, Haguenau M, et al. "AICLA" controlled trial of aspirin and dipyridamole in the secondary prevention of atherothrombotic cerebral ischemia. Stroke. 1983;14(1):5-14.

98. Diener HC, Bogousslavsky J, Brass LM, et al. Aspirin and clopidogrel compared with clopidogrel alone after recent ischaemic stroke or transient ischaemic attack in high-risk patients (MATCH): randomised, double-blind, placebo-controlled trial. Lancet. 2004;364(9431):331-337.

99. Diener HC, Cunha L, Forbes C, Sivenius J, Smets P, Lowenthal A. European Stroke Prevention Study. 2. Dipyridamole and acetylsalicylic acid in the secondary prevention of stroke. J Neurol Sci. 1996;143(1-2):1-13

100. Farrell B, Godwin J, Richards S, Warlow C. The United Kingdom transient ischaemic attack (UK-TIA) aspirin trial: final results. J Neurol Neurosurg Psychiatry. 1991;54(12):1044-1054.

101. ESPRIT Study Group, Halkes PH, van Gijn J, Kappelle LJ, Koudstaal PJ, Algra A. Aspirin plus dipyridamole versus aspirin alone after cerebral ischaemia of arterial origin (ESPRIT): randomised controlled trial. Lancet. 2006;367(9523):1665-1673.

102. EAFT (European Atrial Fibrillation Trial) Study Group. Secondary prevention in non-rheumatic atrial fibrillation after transient ischaemic attack or minor stroke. Lancet. 1993;342(8882):1255-1262.
Vascular Health and Risk Management

\section{Publish your work in this journal}

Vascular Health and Risk Management is an international, peerreviewed journal of therapeutics and risk management, focusing on concise rapid reporting of clinical studies on the processes involved in the maintenance of vascular health; the monitoring, prevention and treatment of vascular disease and its sequelae; and the involvement of

\section{Dovepress}

metabolic disorders, particularly diabetes. This journal is indexed on PubMed Central and MedLine. The manuscript management system is completely online and includes a very quick and fair peer-review system, which is all easy to use. Visit http://www.dovepress.com/ testimonials.php to read real quotes from published authors. 